
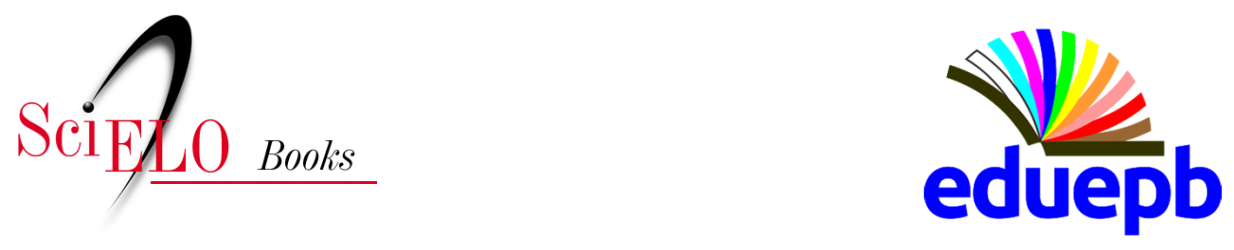

\title{
Leitura Contextualizada de Fontes Primárias Subsídios para Incluir a História das Ciências em Situações de Ensino
}

\author{
Breno Arsioli Moura
}

\section{SciELO Books / SciELO Livros / SciELO Libros}

MOURA, B. A. Leitura Contextualizada de Fontes Primárias: Subsídios para Incluir a História das Ciências em Situações de Ensino. In: SILVA, A. P. B., and MOURA, B. A., eds. Objetivos humanísticos, conteúdos científicos: contribuições da história e da filosofia da Ciência para o ensino de Ciências [online]. Campina Grande: EDUEPB, 2019, pp. 317-355. ISBN: 978-85-78795-79-5. http://doi.org/10.7476/9786586221664.0011.

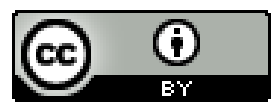

All the contents of this work, except where otherwise noted, is licensed under a Creative Commons Attribution 4.0 International license.

Todo o conteúdo deste trabalho, exceto quando houver ressalva, é publicado sob a licença Creative Commons Atribição 4.0.

Todo el contenido de esta obra, excepto donde se indique lo contrario, está bajo licencia de la licencia Creative Commons Reconocimento 4.0. 


\title{
LEITURA CONTEXTUALIZADA DE FONTES PRIMÁRIAS: SUBSÍDIOS PARA INCLUIR A HISTÓRIA DAS CIÊNCIAS EM SITUAÇÕES DE ENSINO
}

\author{
Breno Arsioli Moura \\ Universidade Federal do $A B C$ - UFABC \\ breno.moura@ufabc.edu.br
}

\section{Introdução}

$\mathrm{N}$ ão é novidade que a história das ciências tem ocupado um lugar significativo nas últimas décadas, com trabalhos de naturezas, perspectivas e fundamentos diversos, mostrando suas potencialidades para melhorar o ensino de conceitos e ideias científicas, bem como sobre o desenvolvimento da própria ciência (MATTHEWS, 2014). Os demais capítulos desse livro, aliás, corroboram essa afirmação. No entanto, não é exagero reafirmar que a consciência de que a inclusão de aspectos históricos das ciências no ensino é relevante em diferentes aspectos não implica na solução de todos os problemas da educação científica. Há muitos nichos a serem explorados, sendo um deles a questão do como. Se é um relativo consenso que a história das ciências tem seu valor para o ensino, como implementá-la ou como obter dela seu máximo potencial são algumas das questões em constante discussão ${ }^{81}$. É por esse caminho que segue a proposta apresentada neste capítulo.

81 O levantamento feito por Teixeira et al., (2012) mostra como ainda é incipiente o número de trabalhos que abordam o como implementar a história das ciências 
As protagonistas da proposta apresentada nesse capítulo são as fontes primárias da história da ciência, em especial, textos escritos, tais como artigos, cartas, manuscritos e livros ${ }^{82}$. Na literatura especializada brasileira, há alguns trabalhos sobre o uso das fontes primárias em situações de ensino (FORATO, 2009; BOSS, 2011; BATISTA et al., 2015; BOSS et al., 2016). Em geral, eles apontam as potencialidades das fontes primárias, mas alertam sobre as dificuldades inerentes da utilização desse material, tais como, dificuldade na leitura e entendimento de palavras e termos adotados que não são mais empregados, a estrutura textual diferente em relação aos livros e artigos atuais, a barreira da língua, uma vez que ainda há poucas fontes traduzidas para o português ${ }^{83}$, entre outras.

A proposta descrita neste capítulo tem como um de seus objetivos aprimorar os benefícios ressaltados pelos autores citados anteriormente, bem como minimizar as dificuldades no trato das fontes primárias. Entendo que não se trata de uma ideia revolucionária ou totalmente nova. Meu propósito é estruturar e fundamentar a partir de alguns referenciais algo que possivelmente já vem sendo aplicado por diversos pesquisadores e professores na interface entre história das ciências e ensino. Certamente, toda a proposta está sujeita a modificações, adaptações e críticas e entendo isso como algo natural da pesquisa científica e historiográfica.

no ensino.

82 Essa especificação é fundamental, uma vez que fontes primárias podem englobar filmes, relatórios, planos, atas, diários etc (KRAGH, 2001, p.134-135). Para esses materiais, cuja estrutura textual e argumentativa pode diferir muito de um artigo, por exemplo, considero a proposta apresentada neste artigo não aplicável.

83 Há, no entanto, cada vez mais iniciativas que buscam minimizar essa questão, por exemplo, em Silva e Guerra (2015) e Silva e Silveira (2018), além de várias traduções publicadas em revistas especializadas, tais como a Scientiae Studia, a Revista Brasileira de Ensino de Física e o Caderno Brasileiro de Ensino de Física. 
A proposta de leitura contextualizada de fontes primárias (LC) está fundamentada no conceito de ensino contextualizado desenvolvido a partir de Klassen (2006) e adaptado em alguns de meus trabalhos (MOURA, 2012; MOURA; SILVA, 2014; 2018). De maneira geral, a LC envolve analisar uma fonte primária a partir de dois contextos - científico e metacientífico -, buscando trabathar questões acerca da natureza da ciência $(\mathrm{NdC})$. Para a discussão deste capítulo, uso como exemplo para a LC o episódio envolvendo Benjamin Franklin (1706-1790) e o experimento da pipa. A aplicação dessa LC foi feita de maneira piloto na disciplina "Evolução da Física", oferecida a todos os alunos da UFABC, onde leciono atualmente. A partir disso, espero que ao leitor sejam ofertados subsídios para que outras LCs possam ser implementadas, discutidas e adaptadas em outros contextos de ensino, promovendo a ampla utilização das fontes primárias da história das ciências.

\section{Do "ensino contextualizado" de Klassen até a leitura contextualizada (LC)}

O conceito de leitura contextualizada (LC) teve origem por volta de 2011, ao longo da elaboração da Abordagem Multicontextual da História da Ciência (AMHIC), desenvolvida em meu doutoramento. A AMHIC foi uma proposta de ensino contextualizado de conteúdos históricos, aplicada a licenciandos em física de uma universidade pública brasileira, com o propósito de fomentar uma formação crítico-transformadora (MOURA, 2012; MOURA; SILVA, 2014; 2018). A fim de fundamentar e definir o que entendia por "contexto", "contextualização" e "ensino contextualizado", utilizei como um dos referenciais teóricos o trabalho de Klassen (2006), pesquisador canadense amplamente reconhecido pelo seu trabalho com narrativas para o ensino de conceitos científicos.

O trabalho de Klassen (2006) tem como base a proposta de Problema de Amplo Contexto, desenvolvida na década de 1970 
por Arthur Stinner e aplicada com alunos canadenses ao longo das décadas seguintes ${ }^{84}$. Segundo Klassen (2006, p.31, tradução livre), "a ideia de contextualizar o conteúdo ensinado tem se tornado um tipo de mantra para vários movimentos de reforma [educacional]". Klassen aborda as críticas aos modelos tradicionais de ensino, baseados no ensino e aprendizagem apenas de conceitos científicos descontextualizados e aponta a significativa oposição do movimento construtivista. Seguindo as perspectivas desse movimento, que enaltece a importância do contexto no processo de ensino e aprendizagem de ciências, ele propôs construir um referencial teórico para o ensino contextualizado.

Klassen (2006, p.35, tradução livre) define contexto como "as entidades que se conectam com ou rodeiam uma entidade focal e contribuem para a significação do todo". Segundo ele, a entidade focal poderia ser, por exemplo, uma habilidade ou conceito científico. Partindo desta definição e buscando construir um referencial teórico para elaborar propostas utilizando os Problemas de Amplo Contexto, Klassen delineou uma metodologia baseada em abordagens contextualizadas para ensinar conceitos científicos a estudantes de ensino médio, a qual denominou de Abordagem Contextualizada Guiada por Narrativas (SCDA) ${ }^{85}$. Para ele, a contextualização no ensino de conceitos científicos pode ser alcançada se o processo de ensino e aprendizagem levar em conta cinco contextos importantes: prático, teórico, social, histórico e afetivo.

Em relação ao contexto prático, Klassen (2006) defende que o modelo de ensino prático deve ser aquele em que o estudante desempenhe o papel de cientista aprendiz, tendo como referência a ideia de que "o trabalho prático é autêntico, no sentido de ser semelhante àquele realizado por cientistas em atividade"

84 Do inglês, Large Context Problem. Para mais detalhes sobre essa proposta, ver Stinner (2006) ou < http://www.arthurstinner.com/> (acesso em fev. 2019).

85 Do inglês, Story-Driven Contextual Approach. 
(KLASSEN, 2006, p.41, tradução livre). Nessa perspectiva, haveria contextualização, uma vez que não seria levado em conta apenas os produtos da ciência - ideias, leis, teorias - mas todo o processo que norteia suas construções. Sobre o contexto teórico, Klassen indica que o processo de compreensão de um fenômeno vai além da percepção sensorial, trazendo à tona a ideia da estreita relação entre teoria e observação. Segundo ele, em uma abordagem contextualizada, a perspectiva teórica de um conceito ou habilidade científica também contribui para colocar o estudante no papel de um cientista aprendiz, visto que o estudo conceitual de um problema também faz parte do trabalho científico e do processo de construção da ciência.

No contexto social, Klassen (2006) se debruça sobre a questão do trabalho cooperativo entre os estudantes, uma vez que a colaboração também é parte do fazer científico: "[...] cada membro deve acreditar que ele ou ela não pode ser bem sucedido sem os outros membros e vice-versa" (KLASSEN, 2006, p.46, tradução livre). Para sustentar a importância do contexto social, o autor utiliza como base a ideia de que a aprendizagem é resultado da interação social, presente nos trabalhos de Lev Vygotsky (18961934) ${ }^{86}$. Uma abordagem contextualizada da ciência deve levar em conta atividades em grupo, de modo a possibilitar uma melhor socialização e intercâmbio de ideias e experiências entre os estudantes. Por sua vez, o contexto histórico envolveria a inclusão de conteúdos históricos na discussão do conceito ou habilidade científica central, a entidade focal em sua proposta. Klassen menciona, entre outros pontos, o valor das fontes primárias, ligando novamente à ideia de ter o estudante como um cientista aprendiz. Contudo, o autor aponta para as possíveis dificuldades no

86 Para mais detalhes, ver Vygotsky (2008). 
uso destas fontes, principalmente em relação aos seus estilos de linguagem e ao conteúdo matemático.

Por fim, o contexto afetivo relaciona-se com o engajamento dos estudantes. Segundo Klassen (2006), para que o estudante se envolva na aprendizagem dos conceitos científicos, deve haver uma ligação emocional entre ele e o conceito envolvido. Para que ele aprenda, ele deve querer aprender. A fim de promover esta motivação, Klassen (2006) destaca o valor do uso de narrativas. Em outro trabalho, Klassen definiu as narrativas como "uma descrição coerente de uma sequência temporal de eventos que possuem um elemento intencional ou causativo e relata a progressão a partir de um estado inicial, passando por um evento intermediário, até um estado final" (2010, p.307, tradução livre). Para ele, embora os demais contextos conversem naturalmente entre si, é crucial o envolvimento do aluno na atividade, e isso pode ser obtido com o uso das narrativas. Ao ouvir ou ler uma narrativa, o aluno seria encorajado a participar das experiências vividas pelo protagonista, o que facilitaria seu aprendizado e seu engajamento.

Definidos os cinco contextos importantes para ensinar, Klassen (2006) apresentou a metodologia SDCA. Em linhas gerais, a proposta baseia-se na apresentação de uma narrativa científica, que engajaria os estudantes - com suas ideias e concepções prévias - em atividades imersas nesses cinco contextos e teria como entidade focal um conceito ou habilidade científica. Por meio da supervisão do professor na realização das atividades, os estudantes desenvolveriam novas ideias e atitudes em relação à ciência. A representação gráfica original pode ser vista na Figura 1. 
Figura 1 - Esquema apresentado por Klassen (2006, p.56) representando graficamente a Abordagem Contextual Guiada por Narrativas (SDCA).

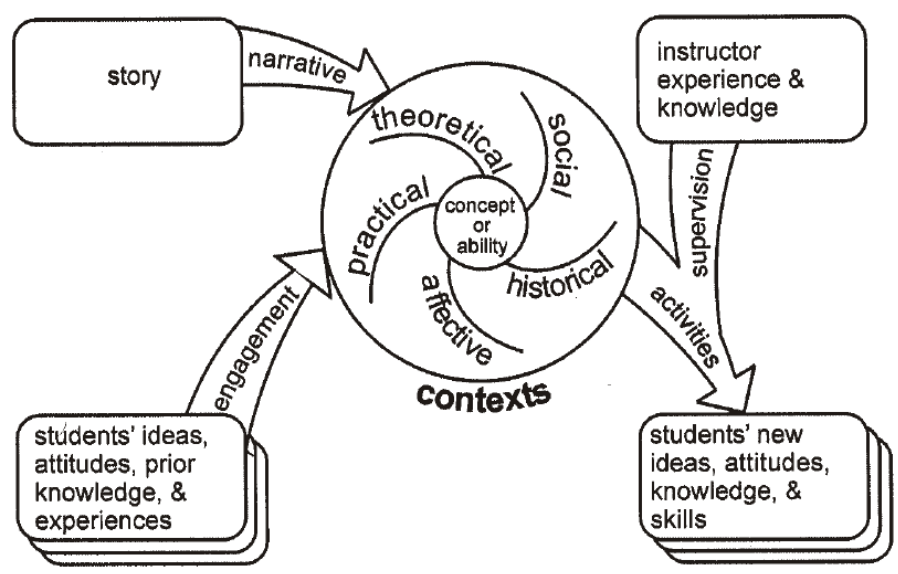

Como uma proposta de referencial teórico, o trabalho de Klassen (2006) ganhou diferentes interpretações e caminhos ao longo dos anos. O próprio autor, por exemplo, avançou a discussão de outros pontos, especialmente a ideia de narrativas, apresentando em trabalhos os seguintes exemplos com viés histórico (KLASSEN, 2007; 2009). No Brasil, Schiffer e Guerra (2015) trabalharam sobre sua proposta, considerando o uso de narrativas históricas para o ensino de assuntos ligados à eletricidade.

Particularmente, considero o aspecto mais relevante de sua proposta a compreensão de contexto e contextualização. Ao invocar os contextos como agentes que dão sentido a um elemento central, Klassen (2006) elucida, ao mesmo tempo, a pluralidade de interpretações e perspectivas e a possibilidade de conectá-las a partir de algo em comum. Partindo disso, desenvolvi a AMHIC, citada no começo dessa seção. A abordagem envolveu o estudo de episódios históricos a partir de três contextos, científico - esse, 
dividido em uma vertente prática e outra teórica -, metacientífico e pedagógico, em um viés problematizador.

O contexto científico é a dimensão de estudo dos episódios históricos em que são analisados os conceitos científicos imersos nele. Isso não se reduz ao entendimento acrítico dos conceitos, como regras a serem decoradas, mas à compreensão de sua gênese, estrutura e validade dentro do contexto em que foi produzido. $\mathrm{O}$ estudo dos episódios históricos por meio do contexto científico aproxima a historicidade do conhecimento, ao deixar claro que todo conhecimento é, por si só, histórico e, portanto, mutável. Já o contexto metacientífico envolve olhar para os episódios de fora, procurando estabelecer a presença de aspectos históricos, epistemológicos, filosóficos, sociológicos e culturais no desenvolvimento do conhecimento científico, ou seja, trata de questões da natureza da ciência (NdC). Complementa-se, assim, a visão introduzida a partir do contexto científico. Por fim, na AMHIC, o contexto pedagógico é constituído de momentos que fomentem a construção de saberes didático-pedagógicos para que o licenciando mobilize sua atitude crítico-transformadora em sua futura prática docente; é olhar para a historicidade do conhecimento pela lente da sala de aula.

Em certo sentido, essa abordagem pretendeu ser uma expansão do contexto histórico da proposta original de Klassen, mas voltada ao ensino superior. Ela abarcou, inclusive, extensa discussão de fontes primárias de Christiaan Huygens (1629-1695), Isaac Newton (1642-1727), Alessandro Volta (1745-1827) e Thomas Young (1773-1829) sobre a óptica e eletricidade. As fontes compreenderam manuscritos, artigos e extratos de livros ${ }^{87}$. No quadro 1 a seguir, está delineado como o episódio envolvendo a pilha de Volta foi trabalhado por meio dos contextos da AMHIC. Nesse

87 Os materiais de Huygens, Newton e Volta já contavam com tradução para o português. Trechos dos trabalhos de Young foram traduzidos por mim e posteriormente publicados (MOURA; BOSS, 2015). 
caso, foi utilizada como fonte primária o artigo de Volta publicado em 1800 e traduzido por Magnaghi e Assis (2008).

Quadro 1 - Esquema geral dos assuntos trabalhados em cada um dos contextos da AMHIC para o episódio de Volta e sua pilha voltaica.

\begin{tabular}{|c|c|c|}
\hline \multirow[b]{2}{*}{$\begin{array}{l}\text { Contexto } \\
\text { científico }\end{array}$} & $\begin{array}{l}\text { Vertente } \\
\text { teórica }\end{array}$ & $\begin{array}{l}\text { 1. Conceituação do modelo explicativo de Galvani } \\
\text { sobre o "fluido nervoso“ das rãs e os pressupostos } \\
\text { teóricos que levou em conta (como, por exemplo, } \\
\text { a ideia de „atmosfera elétrica“ ou de eletricidade } \\
\text { como fluido). } \\
\text { 2. As ideias de Volta de que os metais atraíam eletri- } \\
\text { cidade e a transmitiam através das rãs quando toca- } \\
\text { vam nelas e os conceitos relacionados à pilha por ele } \\
\text { desenvolvida. }\end{array}$ \\
\hline & $\begin{array}{l}\text { Verte } \\
\text { práti }\end{array}$ & $\begin{array}{l}\text { 1. Análise dos experimentos com as rãs e com outros } \\
\text { animais, que cuidados eram tomados e que fenôme- } \\
\text { no era observado. } \\
\text { 2. Estudo sobre os instrumentos desenvolvidos por } \\
\text { Volta no intuito de detectar eletricidade nos metais, } \\
\text { como o eletrômetro e o eletróforo. } \\
\text { 3. Discussão sobre a estrutura e funcionamento da } \\
\text { pilha desenvolvida por Volta, dos metais utilizados, } \\
\text { das condições necessárias para que a pilha produzis- } \\
\text { se fenômenos notáveis etc. }\end{array}$ \\
\hline Cor & \multicolumn{2}{|c|}{$\begin{array}{l}\text { 1. Discussão sobre as evidências produzidas e as interpretações } \\
\text { diferentes dadas por Galvani e Volta; } \\
\text { 2. A influência da invenção da pilha em outros âmbitos da socie- } \\
\text { dade, como a medicina e a literatura. }\end{array}$} \\
\hline $\begin{array}{l}\text { Conte } \\
\text { pedag }\end{array}$ & \multicolumn{2}{|c|}{$\begin{array}{l}\text { 1. Contribuição do episódio histórico para o ensino do funcio- } \\
\text { namento de pilhas e baterias, levando em conta como seu de- } \\
\text { senvolvimento foi consequência do estudo sobre eletricidade } \\
\text { animal. } \\
\text { 2. Possibilidade de análise interdisciplinar do episódio, entre as } \\
\text { áreas de Física, Química e Biologia. }\end{array}$} \\
\hline
\end{tabular}

Fonte: Moura (2012, p.160-161).

Nessa aplicação, percebi a necessidade de "contextualizar" as fontes, ou seja, não poderia simplesmente entregá-las aos estudantes e esperar que as lessem sem quaisquer dificuldades. Tomando como base a referência de ensino contextualizado adotada no plano mais geral da AMHIC, busquei ao longo das atividades inserir as fontes em seus respectivos contextos, analisando as discussões dos 
autores e explicando termos utilizados na época. As dificuldades na leitura das fontes foram notáveis e muito semelhantes às apontadas pela literatura no tema.

Nos anos seguintes a essa aplicação piloto, continuei trabalhando com fontes primárias na graduação e pós-graduação, priorizando artigos e livros. $\mathrm{Na} \mathrm{UFABC}$, atuando nas disciplinas "Nascimento e Desenvolvimento da Ciência Moderna", "Evolução da Física" e "Tópicos em História das Ciências e da Matemática", analisei com os alunos fontes das mais diferentes áreas e autores, além dos citados anteriormente, por exemplo, Aristóteles (384 a.C.-322 a.C.), Ptolomeu (c.100 d.C. - c.170 d.C.), Nicolau Copérnico (1473-1543), Galileo Galilei (1564-1642), Abraham Trembley (1710-1784), Antoine Lavoisier (1743-1794), Joseph Priestley (1733-1804), Michael Faraday (1791-1867) e Albert Einstein (1879-1955). Grande parte dessas fontes, felizmente, foi traduzida para o português por historiadores da ciência ou tradutores profissionais. As atividades com fontes primárias envolviam, basicamente, uma leitura prévia do texto e, posteriormente, uma análise minuciosa de pontos relevantes de seus conteúdos. Foi cada vez mais notável a potencialidade das fontes para trabalhar questões de $\mathrm{NdC}$, principalmente para apontar a mutabilidade das ideias científicas, as nuances da comunicação do cientista com seus pares, o papel da sociedade, da cultura e da política, entre outros.

Com o propósito de explorar todas essas potencialidades, um primeiro esboço de LC foi criado, em meados de 2017. Minha intenção foi estruturar os procedimentos costumeiramente trabalhados, dando a eles nomes, ordem e significações. O primeiro esboço abrangeu uma carta de Galileo a Benedetto Castelli (15781643) sobre a ciência e a religião, incluída no livro Ciência e Fé (GALILEI, 1988). O objetivo dessa LC foi apresentar e discutir os principais argumentos do filósofo natural italiano acerca da relação entre o conhecimento filosófico da natureza e o conhecimento religioso. A partir disso, intencionei problematizar a relação entre ciência e fé, mostrando que essa interação poderia ser complexa 
e mutável. Essa LC foi aplicada em duas turmas da disciplina "Nascimento e desenvolvimento da ciência moderna" ao longo daquele ano. A estrutura e fundamentação da LC foram então aprimoradas, tomando a forma apresentada nas próximas seções.

\section{Construindo a proposta de leitura contextualizada de fontes primárias (LC) a partir de um exemplo: Benjamin Franklin e a pipa}

Nesta seção, abordarei as cinco etapas da construção da proposta de leitura contextualizada de fontes primárias (LC), utilizando como exemplo o episódio histórico envolvendo Benjamin Franklin e o experimento da pipa. A escolha por discutir a preparação por meio de um exemplo - e não simplesmente apresentando as etapas de modo generalizado - deu-se por permitir de antemão apontar os desafios e requisitos envolvidos na construção da LC. Ademais, a própria estruturação da fase de preparação - e também da aplicação, como descreverei na próxima seção - ocorreu ao mesmo tempo da definição das etapas, ou seja, não se definiu as etapas para depois encaixar o exemplo; foram dois processos complementares e simultâneos.

Antes de abordar as etapas, é necessário tecer um breve comentário acerca das circunstâncias que precederam a construção da LC. Assim como a disciplina "Nascimento e Desenvolvimento da Ciência Moderna", "Evolução da Física" é disciplina de caráter optativo e aberta a todos os estudantes da universidade. Como todas as disciplinas da UFABC, "Evolução da Física" deve ser trabalhada ao longo de doze semanas, que compõem o quadrimestre letivo ${ }^{88}$. Por ser a única disciplina de história da física na instituição, ela possui uma ementa aberta, que permite ao docente escolher episódios que julgue mais relevantes. Dessa maneira, como docente da disciplina desde 2014, geralmente a dividi em

88 Para mais detalhes da estrutura curricular da UFABC, sugiro a leitura de Xavier e Steil (2018). 
quatro blocos, sendo três deles fixos: astronomia/mecânica, óptica e eletricidade. $\mathrm{O}$ quarto bloco abordou, em alguns anos, a física moderna e, em outros, a termodinâmica. No bloco dedicado à eletricidade, foi dada ênfase desde o início na consolidação da área, ao longo do século XVIII, principalmente na Europa. Nas primeiras vezes em que ofertei a disciplina, foram consideradas principalmente as contribuições de Stephen Gray (1666-1736), Charles Du Fay (1698-1739) e Jean-Antoine Nollet (17001770), com alguma discussão pontual sobre Franklin. Mais ao final do bloco, a área foi estendida, abordando também questões do galvanismo e do eletromagnetismo, especialmente os trabalhos de Luigi Galvani (1737-1798), Alessandro Volta (1745-1827) e Hans Christian Ørsted (1777-1851)

Por volta de 2014, comecei a trabalhar mais intensamente com as ideias de Franklin, inicialmente sobre luz, e posteriormente sobre eletricidade. Após uma longa imersão na historiografia da eletricidade do século XVIII, nos estudos e na vida de Franklin e em questões de teoria da história e de tradução, foram feitas as primeiras traduções de seus textos. Não havia, até aquele momento, nenhuma tradução integral de textos científicos de Franklin para o português ${ }^{90}$. Um primeiro resultado foi publicado em Moura e Bonfim (2017) e o conjunto completo de traduções em Moura $(2019)^{91}$. Dessa maneira, concluí que a LC poderia ser uma boa oportunidade de trabalhar esses textos em situações de ensino,

89 O trabalho com todos esses autores só foi possível porque há boa literatura em português sobre eles, inclusive com traduções de seus trabalhos (BOSS; CALUZI, 2007; MAGNAGHI; ASSIS, 2008; BOSS et al., 2012).

90 O único texto de Franklin em português até então era sua autobiografia, cuja primeira edição traduzida foi publicada na década de 1950 e pode ser encontrada até os dias atuais, em diferentes editoras.

91 Para uma parte das traduções, contei com o apoio da discente Thátyusce Bonfim, que recebeu entre 2014 e 2016 uma bolsa de Iniciação Científica da Fundação de Amparo à Pesquisa do Estado de São Paulo (FAPESP). 
além de apresentar aos alunos materiais desse autor em português, em primeira mão. A partir de 2016, a parte do bloco de eletricidade destinada à Franklin foi ampliada e a LC com seus materiais começou a ser elaborada.

\section{Primeira etapa: a escolha do tema e da fonte}

A primeira etapa da preparaçãoda $\mathrm{LC}$ é a escolha do tema e da fonte que será utilizada nas atividades. O tema selecionado foi o episódio envolvendo Franklin e o experimento da pipa. Desde que Franklin começou a ocupar um lugar de destaque no bloco de eletricidade da disciplina "Evolução da Física", o episódio da pipa foi trabalhado, embora não com minúcia. Pelo fato de ele compor uma das anedotas mais famosas da história da ciência, concluí que seria uma chance de problematizá-lo com os estudantes, a fim de minimizar visões históricas distorcidas (GIL-PÉREZ et al., 2001). As versões mais comuns do episódio dizem que Franklin empinou uma pipa em meio a uma grande tempestade, com o propósito de confirmar a natureza elétrica dos raios. Com um raio atingindo a pipa e tendo comunicado sua eletricidade por meio de uma chave na outra extremidade do barbante, Franklin teria provado que os raios são semelhantes às descargas elétricas provocadas por garrafas de Leiden ${ }^{92}$, diferindo apenas na dimensão. Uma das diversas gravuras ilustrando o experimento pode ser conferida na Figura 2.

92 Garrafas de Leiden foram um tipo primordial de capacitor, tendo sido inventadas na década de 1740. Sobre esse instrumento, ver Guerra e Jardim (2017) e Silva e Heering (2018). 
Figura 2 - Franklin e o experimento da pipa.

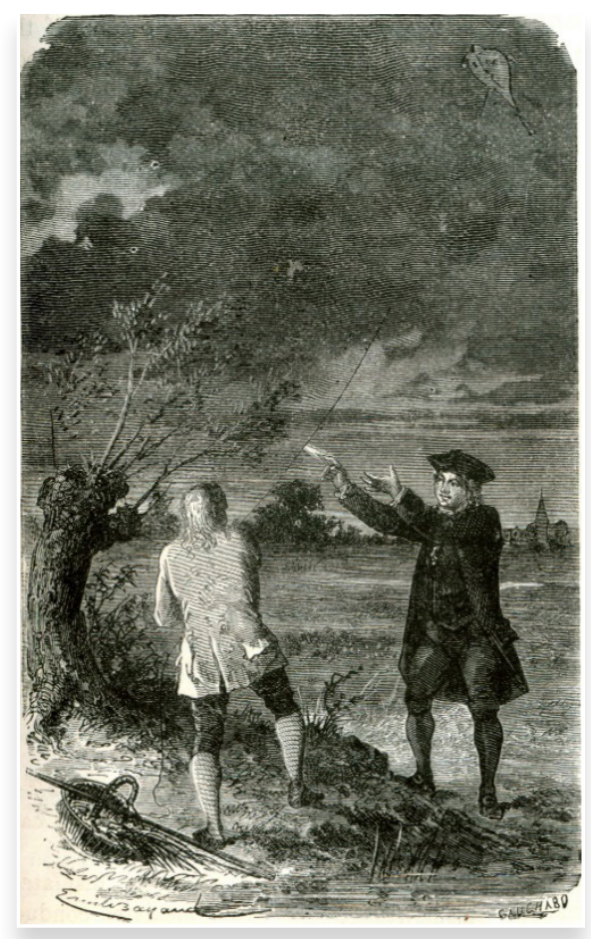

Fonte: Cooley (1882, p.159)

Há poucos relatos fidedignos sobre a realização do experimento. Os mais completos são aqueles apresentados pelo próprio Franklin em uma carta de 1752 dirigida a seu correspondente na Grã-Bretanha, Peter Collinson (1694-1768), e publicada nas Philosophical Transactions da Royal Society (Franklin, 1752), e o de Joseph Priestley (1733-1804), descrito em seu livro sobre história da eletricidade até o século XVIII (PRIESTLEY, 1767, p.180181). A carta, como será mostrado mais adiante, é bastante sucinta e apenas descreve como a pipa deve ser construída e mais algumas orientações complementares. A descrição de Priestley, por outro lado, é mais detalhada, e menciona até mesmo a participação de 
um dos filhos de Franklin. As sucessivas distorções desse episódio têm gerado uma série de visões inadequadas sobre a natureza do trabalho científico, refletidas, por exemplo, em materiais didáticos (SILVA; PIMENTEL, 2008). A historiografia moderna sobre os trabalhos de Franklin tem contribuído para compreender mais adequadamente esse episódio e colocá-lo à luz de sua época (HEILBRON, 1970; COHEN, 1990).

Atrelada ao tema de estudo, está a escolha das fontes. De maneira geral, recomendo a escolha de fontes com traduções profissionais para o português, publicadas em livros ou em revistas especializadas. Nesse caso específico, utilizei minha própria tradução, mas ressalto que elas foram frutos de um demorado processo de pesquisa, descrito anteriormente, além de ter levado em conta características do ato tradutório (GROSSMAN, 2010). Traduzir um texto não é simplesmente passar de uma língua a outra, mas um processo que envolve compreender o conteúdo do material, sua mensagem, as prerrogativas e trajetória pregressa do autor ou autora, tornando o material traduzido um verdadeiro ato de criação (GUERRINI, 2018).

Alicerçado nesses pontos, defini as três fontes primárias que seriam trabalhadas na LC. Três delas fazem parte do livro de Franklin sobre eletricidade, o Experiments andobservations on electricity, made at Philadelphia in America, publicado em $1751^{93}$. A primeira é o ensaio "Opiniões e conjecturas sobre as propriedades e efeitos da matéria elétrica”, escrito em 1749. Nesse extenso ensaio, Franklin escreveu sobre suas principais ideias em eletricidade e imaginou, de maneira mais formal que em escritos anteriores, experimentos e situações que poderiam mostrar que nuvens em

93 Ao contrário do que geralmente se imagina, o Experiments and observations não foi propriamente um tratado em eletricidade. Ele foi constituído de cartas enviadas por Franklin a Collinson desde 1747 e publicado com o auxílio desse último. Ao todo, foram publicadas cinco edições em inglês do livro, a última em 1774. Edições em alemão, italiano e francês também foram publicadas nesse intervalo. 
tempestades estariam eletrizadas e que os raios poderiam ser descargas elétricas como as produzidas por garrafas de Leiden. Dentre eles, estava o que ficou conhecido como "experimento da guarita". Nesse experimento, uma guarita era colocada no topo de um edifício, e dela saia uma haste vertical metálica pontuda. $\mathrm{O}$ experimentador dentro da guarita, sobre um suporte isolante, poderia perceber faíscas assim que nuvens em uma tempestade passassem por cima da haste. Um detalhe essencial: Franklin não pressupôs a incidência de raios sobre a haste, mas imaginou que ela funcionasse simplesmente como um coletor de eletricidade das nuvens. No "Opiniões e conjecturas", o experimento foi apenas idealizado por Franklin; mais tarde, em 1752, ele foi reproduzido com sucesso na França. A segunda fonte é a carta de Franklin a Collinson contendo uma descrição do experimento da pipa. Além de ter sido publicada nas Philosophical Transactions em 1752, o texto foi inserido nas edições posteriores do Experiments and observations. Por fim, a terceira fonte é o livro de Priestley sobre história da eletricidade, especificamente seu relato sobre a realização do experimento da pipa. Enquanto o "Opiniões e conjecturas" fornece as ideias iniciais de Franklin para determinar se as nuvens em tempestades estavam eletrizadas ou não, as outras duas fontes apresentam os relatos restritos ao episódio da pipa. Portanto, as três compõem o conjunto necessário para trabalhar a LC no tema escolhido.

\section{Segunda etapa: os conhecimentos prévios necessários à LC}

A segunda etapa da preparação da LC envolve estabelecer os conhecimentos prévios necessários para trabalhar com a fonte. Esses conhecimentos prévios podem ser de vários tipos e fornecem as informações essenciais para que o conteúdo da fonte possa ser compreendido e estudado. Fontes que trabalhem com temas ou conceitos hoje considerados obsoletos, por exemplo, necessitam de explicações prévias, a fim de que os participantes 
saibam quais eram os pressupostos e ideias da época em que elas foram produzidas e porque não são aceitos mais. De maneira complementar, em determinados casos, é preciso detalhar questões sociais, culturais, políticas etc., da época, a fim de entender os papéis desempenhados pelas fontes e por seus autores antes de discuti-los propriamente.

Para essa LC, foram definidos quatro conhecimentos prévios necessários: as ideias precedentes ao trabalho de Franklin e seus conceitos de um único fluido elétrico, do poder das pontas e da formação de tempestades. Descrevo nos trechos sequentes aspectos gerais desses conhecimentos e recomendo a leitura de estudos historiográficos específicos sobre Franklin e a eletricidade no século XVIII, a fim de complementar a discussão (HEILBRON, 1970; COHEN, 1990; ASSIS, 2010; MOURA, 2019). O leitor deve estar atento também para o fato de que os conceitos de Franklin discutidos a seguir estão obsoletos, ou seja, não compreendem a moderna concepção sobre a eletricidade e seus fenômenos.

Em relação às ideias precedentes de Franklin, foi considerado fundamental examinar a situação da eletricidade no século XVIII e as ideias de três autores: Gray, Du Fay e Nollet. Presumi que o conhecimento dessas questões seria importante para situar o trabalho de Franklin e sua importância no contexto dos estudos em eletricidade da época. A respeito de Gray, Du Fay e Nollet, esses autores contribuíram para estabelecer a eletricidade como um campo particular de estudos, descrevendo as principais propriedades e fenômenos elétricos. Foi por meio deles, por exemplo, que se notou a transmissão da eletricidade de um corpo a outro, a existência de corpos mais propensos a transmiti-la que outros, a repulsão e a atração de corpos eletrizados e as possíveis razões envolvidas etc. Du Fay e Nollet, em particular, distinguiram-se ao propor teorias para a eletricidade e o fluido elétrico. Enquanto o primeiro considerou a existência de dois tipos de eletricidade - vítrea e resinosa -, o segundo considerou a eletricidade como 
um único fluido, afluindo e efluindo dos corpos eletrizados. Com base nessas diferentes perspectivas, ambos buscaram explicar os principais fenômenos elétricos conhecidos. Diversos autores muitos brasileiros, inclusive - estudaram a eletricidade no século XVIII e os conceitos desses três filósofos naturais, cujos trabalhos foram referências para o desenvolvimento dessa etapa da LC (HEILBRON, 1970; COHEN, 1990; ASSIS, 2010; BOSS et al., 2012; SILVA, 2011).

Para a LC, também considerei importante que fossem compreendidos os principais conceitos da teoria elétrica de Franklin, tais como, (1) teoria de um único fluido elétrico ${ }^{94}$; (2) a eletrização positiva e negativa; (3) o poder das pontas; (4) suas ideias sobre o funcionamento da garrafa de Leiden; (5) a formação de temporais com raios e trovões, entre outros ${ }^{95}$. Dentre esses, foram tomados como imprescindíveis os conceitos 1, 3 e 5, detalhados a seguir.

Franklin acreditava que havia apenas um único fluido elétrico - contrariando a ideia de Du Fay, por exemplo -, o qual considerava algo sui generis. Partículas desse fluido se repeliam, mas eram fortemente atraídas por partículas dos corpos comuns. Por isso, todos os corpos tinham uma determinada quantidade de fluido elétrico em si que preenchia seus poros. $\mathrm{O}$ desequilíbrio dessa quantidade - para mais ou para menos - gerava fenômenos elétricos como as descargas ou a atração a pequenos objetos. Por exemplo, quando um corpo recebia mais fluido elétrico que seus poros poderiam comportar, formava-se ao redor dele uma espécie de atmosfera elétrica. Essa atmosfera poderia ser atraída por outro corpo com menos eletricidade que o natural, gerando uma descarga elétrica.

94 Nos textos de Franklin, os termos "fluido elétrico", "fogo elétrico" e "matéria elétrica" são sinônimos.

95 Para uma descrição desses e de outros conceitos de Franklin, ver Moura (2018). 
Atrelado a esse conceito de um único fluido elétrico estava a descrição do poder dos corpos pontudos. Em seus primeiros estudos em eletricidade, comunicados a Collinson por volta de 1747, Franklin já havia descrito esse "maravilho efeito dos corpos pontudos" (MOURA, 2019, p.55). O efeito havia sido notado por um de seus colaboradores, Thomas Hopkinson (1709-1751). Sucintamente, o poder das pontas referia-se à capacidade que corpos pontudos tinham para "extrair" ou "lançar" fluido elétrico (MOURA, 2019, p.55). Segundo Franklin, quando um corpo pontudo era aproximado de um objeto eletrizado, ele "extraía" sua eletricidade; por sua vez, quando era afixado em um objeto, esse último não poderia ser eletrizado, uma vez que as pontas "lançavam” para longe o fluido elétrico. Nas comunicações seguintes, especialmente no ensaio "Opiniões e conjecturas", Franklin explorou mais esse conceito.

Por fim, suas ideias acerca da formação de temporais foram descritas em uma comunicação a Collinson escrita em 1749, antes do "Opiniões e conjecturas". Para Franklin, os temporais com maior incidência de raios e trovões eram formados no mar e, pela ação do vento, vinham para terra firme. Segundo ele, a água atraía fortemente o fluido elétrico e, no mar, ao se atritar com o sal, faria com que esse fluido das partes mais inferiores do oceano fosse para a superfície, deixando essa parte altamente eletrizada. Por consequência, o vapor da água do mar também estaria eletrizado. Esse vapor subindo e se condensando formaria as nuvens de tempestade. Por estarem com excesso de fluido elétrico, essas nuvens o descarregariam assim que se aproximassem de nuvens menos eletrizadas ou montanhas. A perda de fluido elétrico significava a perda da repelência que impedia as partículas de água de se juntarem, por isso, ao serem descarregadas, as nuvens liberavam a chuva. Para Franklin, essa engenhosa concepção explicava, por exemplo, porque as nascentes de grandes rios ficavam perto de montanhas. 


\section{Terceira etapa: definição dos contextos de análise}

A terceira etapa da construção da LC é a definição dos elementos dos contextos de análise. Mantive, nesse ponto, uma estrutura semelhante à da Abordagem Multicontextual da História da Ciência (AMHIC), considerando os contextos científico e metacientífico. Assim como na AMHIC e na concepção original de Klassen (2006), os contextos funcionam na LC como caminhos para a discussão que, quando conectados, oferecem uma compreensão ampla da fonte, de seu conteúdo e de seu processo de criação. De um lado, os elementos do contexto científico indicam quais tópicos, conceitos, ideias, proposições ou discussões científicas podem ser trabalhadas com as fontes. De outro, os elementos do contexto metacientífico recaem na natureza da ciência $(\mathrm{NdC})$, assinalando quais questões acerca do fazer científico são evidentes a partir do estudo da fonte ${ }^{96}$. Assim, ficam claros quais são os assuntos que podem ser trabalhados com a LC, orientando sua aplicação. Para essa LC, os elementos definidos para cada contexto estão listados no quadro 2 a seguir.

96 A literatura sobre $\mathrm{NdC}$ é extensa e variada, com diversas concepções diferentes (HODSON, 2014). Não é meu intuito discorrer sobre esse assunto, mas saliento os elementos de $\mathrm{NdC}$ elencados no quadro 2 são específicos do episódio abordado, não fazendo referência direta a nenhuma das concepções mais conhecidas e debatidas na comunidade dos que estão na interface entre história das ciências e ensino de ciências (falo exclusivamente das concepções conhecidas como "aspectos consensuais", "semelhança familiar" e "ciência integral"). Certamente, o leitor é livre para atrelar os elementos do contexto metacientífico em qualquer uma dessas concepções. 


\section{Quadro 2- Elementos dos contextos científico e metacientífico da}

LC.

\begin{tabular}{|c|l|}
\hline $\begin{array}{c}\text { Contexto } \\
\text { científico }\end{array}$ & - Poder das pontas; \\
\hline & - Eletrização das nuvens. \\
\hline & Os primeiros estudos em um campo de conhecimento não \\
apresentam, imediatamente, todas as suas propriedades; \\
Contexto me- \\
tacientífico
\end{tabular}

\section{Quarta etapa: 0 elemento problematizador}

A quarta etapa abrange determinar o elemento problematizador. Assim como na AMHIC, a problematização objetiva engajar os participantes, fazendo-os mobilizar seus conhecimentos prévios para a solução de um problema (MOURA, 2012, p.95-96). A partir de um viés freireano, a problematização pressupõe que o conteúdo das fontes não será simplesmente dado aos participantes, mas trabalhado de modo que nelas os problemas possam ser elucidados. Trata-se, assim, de uma ação dialógica entre proponente e participante.

Para o exemplo de Franklin e o experimento da pipa, foi definido como elemento problematizador à apresentação de gravuras e pinturas que retratam o experimento da pipa, entre elas, as mostradas nas figuras 2 e 3 . Essa apresentação foi acompanhada das seguintes perguntas: o que as imagens retratam?; quais detalhes chamam a atenção?; o que Franklin parece fazer?. Com isso, esperava-se que os participantes identificassem os principais aspectos das figuras, tais como, a realização do experimento em meio a uma tempestade, a configuração da pipa, a presença da chave, as faíscas, a incidência de raios etc. Somente algumas dessas figuras mostravam todos esses detalhes. A partir disso, foram lançadas 
mais três perguntas: Franklin realmente fez o experimento da pipa?; Se sim, o que levou a propô-lo?; O que teria concluído?.

Figura 3 - O experimento da pipa retratado em quadro de Benjamin West (1738-1820), por volta de 1816. O quadro atualmente faz parte da coleção do Philadelphia Museum of Art.

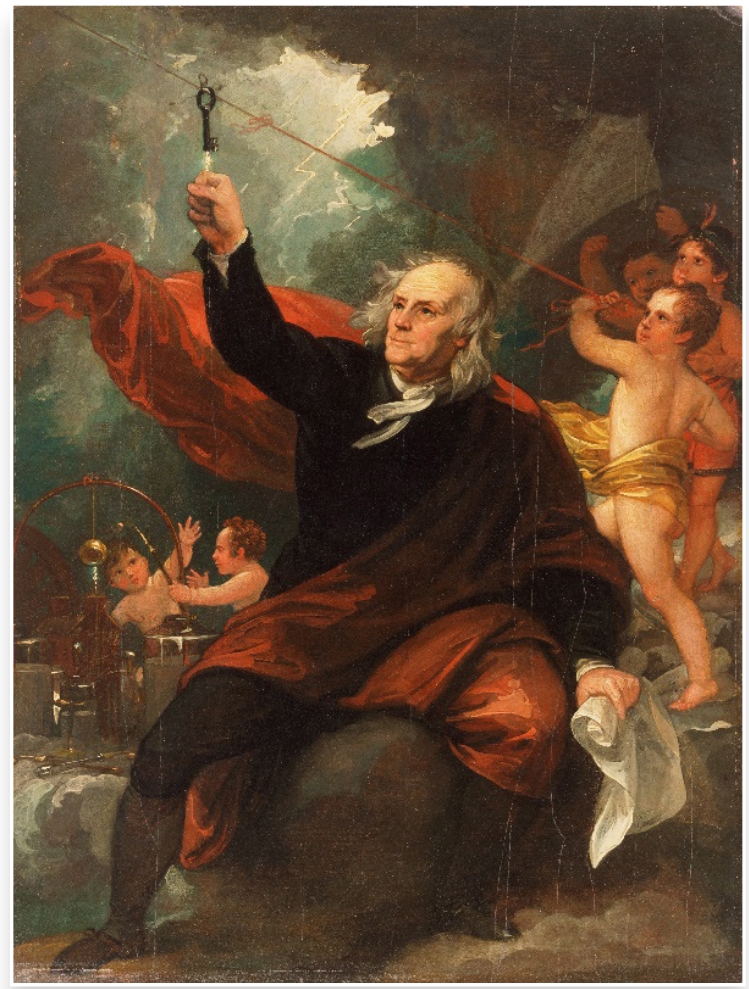

Fonte: $<$ http://www.philamuseum.org/collections/permanent/57044. html>, acesso em abr. 2019. 


\subsection{Quinta etapa: estruturação da LC}

A quinta e última etapa é a estruturação da LC. Com base nas etapas anteriores, trechos da fonte devem ser selecionados e, para cada um deles, é inserido um conjunto de subsídios fundamentados nos elementos dos contextos. Isso significa que cada trecho é esmiuçado, considerando os elementos dos contextos científico e metacientífico. Essa, portanto, é a etapa de sintetização, em que todos os pontos das etapas anteriores se conectam em uma proposta consolidada. A estrutura da LC para o episódio de Franklin e o experimento da pipa está descrita no quadro 3 a seguir ${ }^{97}$. O leitor notará que, para esse episódio, a LC focou mais nos elementos do contexto metacientífico. Para outras LCs, essa ênfase pode ser diferente. A parte dos "Subsídios para a LC" destacam os elementos do contexto científico e do metacientífico, a partir dos símbolos CC e CM, respectivamente. A argumentação buscou trabalhar de maneira integrada os dois contextos, de forma que os principais aspectos das fontes pudessem ser explorados em sua integralidade.

97 Na aplicação na disciplina "Evolução da Física", foram considerados mais trechos do "Opiniões e conjecturas". Por uma questão de espaço, não foram disponibilizados neste capítulo, mas os que foram são suficientes para ilustrar o exemplo. 
Quadro3-A estrutura da LC para o episódio de Franklin e o experimento da pipa. Na parte dos "Subsídios para a LC" foram indicados pelas siglas CC e CM, respectivamente, referências ao contexto científico, ao contexto metacientífico e ao elemento problematizador. Os trechos foram extraídos de Moura (2019), onde os textos de Franklin estão traduzidos para o português. As palavras entre colchetes foram incluídas por mim, a fim de complementar o sentido de uma frase ou termo.

\section{Trecho 1}

\section{Fonte: "Opiniões e conjecturas"}

[...] não poderia o conhecimento desse poder das pontas ser útil para a humanidade, em preservar casas, igrejas, navios etc., do alcance dos raios, por nos direcionar a fixar nas partes mais altas desses edificios hastes verticais de metal, feitas afiadas como uma agulha e douradas para prevenir o enferrujamento, e do pé dessas hastes um fio para baixo do exterior do prédio, para o chão, ou para baixo ao redor de uma das mortalhas de um navio, e para baixo ao lado dela até que ela atinja a água? Essas hastes pontudas provavelmente não extrairiam o fogo elétrico silenciosamente de uma nuvem antes que ela chegasse perto o suficiente para golpear, e assim nos assegurariam desse mal mais súbito e terrivel?

Para determinar a questão se as nuvens que contêm raios estão eletrizadas ou não, eu proporia um experimento para ser tentado onde ele possa ser feito convenientemente. No topo de alguma torre alta ou campanário, coloque um tipo de guarita (como na Fig. 9 $)^{35}$ grande o suficiente para conter um homem e um suporte elétrico. Do meio do suporte, deixe uma haste de ferro subir e passar dobrando para fora da porta, e então para cima $20[\approx 6 \mathrm{~m}]$ ou 30 pés $[\approx 9 \mathrm{~m}]$, a ponta sendo bem afiada no final. Se o suporte elétrico for mantido limpo e seco, um homem de pé em cima dele quando tais nuvens estão passando baixo, poderá ser eletrizado e produzir faíscas, a haste extraindo fogo [elétrico] da nuvem para ele. Se algum perigo ao homem for percebido (embora eu acho que não existiria nenhum) deixe ele ficar no chão de sua guarita, e ocasionalmente traga para perto da haste o laço de um fio que possui uma das extremidades amarradas aos fios condutores [aterrados], ele o segurando por um cabo de cera, tal que as faiscas, se a haste for eletrizada, golpeará da haste para ofio, e não o afetará.

(MOURA, 2019, p.103-104).

98 Figura 4 a seguir. 
Figura 4 - Ilustração original de Franklin. Nela, é possível ver a guarita, uma parte da haste (que se estenderia até bem mais acima) e o suporte isolante onde o experimentador deveria ficar.

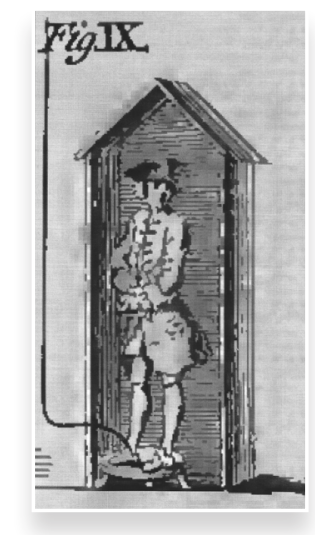

Fonte: Franklin (1769, plate I).

\section{Subsídios para a LC}

Nesse trecho, Franklin descreveu, inicialmente, uma possível utilização rática do poder das pontas e, em seguida, o experimento da guarita. Alguns pontos do trecho destacam-se. Em primeiro lugar, nota-se que Franklin reforçou a necessidade da haste ter uma ponta "bem afiada no final" (CC). Isso significa que ele esperava extrair eletricidade das nuvens, tomando como referência o efeito que corpos pontudos tinham quando aproximados de corpos eletrizados. Se a eletricidade nas nuvens fosse a mesma daquela presente nos corpos comuns, ela também deveria ser extraída por corpos pontudos, segundo sua concepção. Em segundo lugar, percebe-se que Franklin não pareceu considerar o experimento perigoso. Pode-se até imaginar certa negligência nesse sentido, mas vale salientar que, no trecho, Franklin não mencionou a incidência de raios da haste. Ou seja, a princípio, Franklin esperava que a haste extraísse "silenciosamente" o fluido elétrico das nuvens "antes que ela chegasse perto o suficiente para golpear", o que não configuraria uma situação de perigo ao experimentador. De acordo com nosso conhecimento atual sobre a eletricidade, mesmo assim, essa seria uma situação de risco. Isso ressalta como, na época de Franklin, a eletricidade ainda era um campo de conhecimento em construção, com suas propriedades e fenômenos sendo gradualmente estudados e definidos $(\mathrm{CM})$. 
O experimento da guarita é frequentemente associado ao desenvolvimento dos para-raios. É evidente que Franklin percebeu que a haste poderia evitar a incidência de raios, ao retirar a eletricidade das nuvens. Porém, o experimento não foi desenvolvido com essa função, mas a de verificar se essa eletricidade era a mesma produzida por máquinas elétricas e armazenadas em garrafas de Leiden (CM).

O trecho também sugere que Franklin não realizou o experimento na época da redação do "Opiniões e conjecturas". Ao dizer que "proporia", ele possivelmente imaginou que o experimento daria resultados satisfatórios, com base nos seus conceitos de fluido elétrico e de poder das pontas (CC). O experimento foi reproduzido com sucesso na França, em 1752, contribuindo para a popularização de suas ideias entre os europeus. Houve, no entanto, alguns problemas. Por um lado, surgiu o receio de que essa eletricidade das nuvens ou mesmo os raios atingindo a haste pudessem ser acumulados no solo, gerando terremotos. Além disso, nem todas as reproduções foram bemsucedidas. Em 1753, George Wilhelm Richmann (1711-1753) morreu após ter seu aparato atingido por uma descarga elétrica, o que diminuiu um pouco o entusiasmo dos filósofos naturais pelo experimento.

Trecho 2

Fonte: Carta de Franklin a Collinson, contendo a descrição do experimento da pipa

Como frequente menção é feita em artigos públicos da Europa sobre o sucesso do experimento [da] Filadélfia para extrair o fogo elétrico de nuvens por meio de hastes de ferro pontudas erguidas em prédios altos etc., pode ser propicio aos curiosos serem informados que o mesmo experimento foi exitoso na Filadélfia, embora feito de maneira diferente e mais fácil, conforme segue explicado.

Faça uma pequena cruz de duas tiras leves de cedro, os braços tão longos de forma a alcançar os quatro cantos de um largo lenço fino de seda quando estendido. Amarre os cantos do lenço às extremidades da cruz, de modo que tenha o corpo de uma pipa, a qual sendo suprida com uma cauda, laço e barbante, subirá no ar, como aquelas feitas de papel. Porém, essa sendo feita de seda, é mais apropriada para enfrentar a umidade e vento de uma tempestade com raios e trovóes sem rasgar. No topo da tira vertical da cruz deve ser afixado um fio pontudo muito afiado, erguendo-se um pé $[\approx 30 \mathrm{~cm}]$ ou mais acima da madeira. Ao final do barbante, próximo à mão, deve ser amarrado um laço de seda, e onde a seda e o barbante se unem uma chave deve ser amarrada.

A pipa é para ser elevada quando um temporal com raios e trovões parece estar vindo, e a pessoa que segura o barbante deve ficar dentro de uma porta ou janela, ou sob alguma cobertura, tal que a fita de seda não possa ser molhada, e cuidado deve ser tomado para que o barbante não toque a moldura da porta ou janela. Assim que qualquer das nuvens carregadas passar por cima da pipa, o fio pontudo extrairá o fogo elétrico delas, e a pipa, junto com todo o barbante, será eletrizada, e os filamentos soltos do barbante se sobressairão por toda a extensão e serão atraídos por um dedo 
que se aproxima. E quando a chuva tiver molhado a pipa e o barbante, tal que ele possa conduzir livremente o fogo elétrico, você perceberá ele fluindo para fora [o fogo elétrico] abundantemente a partir da chave na aproximação de seu nó dos dedos. Por essa chave, a garrafa [de Leiden] pode ser carregada e pelo fogo elétrico assim obtido, espiritos podem ser excitados, e todos os outros experimentos elétricos ser realizados, os quais são usualmente feitos pelo auxílio de um globo de vidro ou tubo friccionado e, por meio disso, a uniformidade da matéria elétrica com aquela dos raios [é] completamente demonstrada. (MOURA, 2019, p.139-140).

Subsídios para a LC

O trecho anterior corresponde à totalidade da carta de Franklin a Collinson sobre o experimento da pipa. Como mencionei na seção XXX, a carta é breve e contém apenas direções de como construir a pipa. Novamente, percebe-se que Franklin não pensou em um raio atingindo a pipa, mas que ela coletasse fluido elétrico das nuvens da mesma forma que a haste metálica no experimento da guarita. Além disso, friso a menção à facilidade do experimento em relação ao da guarita, o que revela que Franklin o considerou como uma versão desse último. Não há, nesse sentido, uma exclusividade no experimento da pipa (CM). Ressalto, ainda, que o caráter objetivo e essencialmente descritivo do texto sugere que Franklin comunicou a Collinson o experimento não como um grande feito, mas como um simples outro modo de detectar a eletricidade das nuvens em tempestades (CM).

Há outros aspectos da carta igualmente interessantes. Franklin dá a entender que o experimento da pipa foi efetivamente realizado por ele. Não parece haver, até os dias atuais, qualquer confirmação de que Franklin realizou o experimento, gerando controvérsias entre historiadores da ciência. Outrossim, o francês Jacques de Romas (1713-1776) teria pleiteado a concepção do experimento, em uma contenda que Franklin optou por não se envolver. De todo modo, feito ou não, o experimento da pipa não parece ter ocupado lugar de destaque na teoria elétrica de Franklin, pois em sua autobiografia, ele o mencionou apenas uma vez, como uma variante do experimento da guarita (MOURA, 2019, p.138).

Trecho 3

Fonte: Livro de Priestley sobre história da eletricidade, publicado em 1767.

Como cada circunstância relacionada a uma descoberta assim tão capital como essa (a maior, talvez, que foi feita em toda a abrangência da filosofia desde o tempo de Sir Isaac Nerwton) não possa senão dar prazer a todos os meus leitores, devo tentar satisfazê-los com a comunicação de algumas particularidades as quais obtive da melhor autoridade.

O Doutor [Franklin], depois de ter publicado seu método de verificar sua hipótese acerca da igualdade da eletricidade com a substância do raio, estava esperando 
para a instalação de um pináculo na Filadélfia para colocar suas ideias em prática, não imaginando que uma haste pontuda, de tamanho médio, poderia responder a esse propósito, quando isso ocorreu a ele, que, por meio de uma pipa comum, ele poderia ter um acesso mais rápido e melhor às regióes de trovão que por qualquer pináculo que fosse. Preparando, portanto, um lenço de seda largo e duas varetas cruzadas de comprimento apropriado, sobre as quais ele se estende, ele aproveitou a oportunidade da primeira aproximação de uma tempestade com trovoada para caminhar por um campo, no qual havia um abrigo adequado para seu propósito. Mas, temendo o ridiculo o qual tentativas malsucedidas na ciência muito comumente encontram, ele informou seu experimento pretendido a ninguém exceto seu filho, que o ajudou a erguer a pipa.

A pipa sendo erguida, um tempo considerável passou antes que houvesse qualquer sinal dela sendo eletrizada. Uma nuvem muito promissora tinha passado sobre ela sem qualquer efeito. Quando, demoradamente, ele quase estava começando a perder a esperança em seu esquema, observou algumas linhas soltas do barbante de cânhamo ficando eretas e evitando umas às outras, como se tivessem sido suspensas em um condutor comum. Surpreso com essa aparição promissora, ele imediatamente apresentou seu nó [dos dedos] à chave, e (deixe o leitor julgar o extraordinário prazer que deve ter sentido naquele momento) a descoberta estava completa. Ele percebeu uma faísca elétrica muito evidente. Outras [faíscas] sucederam, mesmo antes do barbante estar molhado, tal a colocar o assunto fora de toda disputa, e quando a chuva tinha molhado o barbante, ele coletou fogo elétrico muito copiosamente. Isso aconteceu em junho de 1752, um mês depois que os eletricistas na França tinham verificado a mesma teoria, mas antes de ele ter ouvido qualquer coisa que tivessem feito (MOURA, 2019, p.134-135).

A descrição de Priestley contrasta significativamente com a carta objetiva de Franklin, contendo detalhes não encontrados em outras descrições do estadunidense. Supõe-se que o relato é fidedigno, uma vez que Franklin auxiliou Priestley na concepção do livro (SCHOFIELD, 1997, p.142). Priestley fornece, por exemplo, informações sobre o momento em que Franklin teria empinado a pipa. Além disso, ele menciona a companhia de um dos filhos de Franklin e as razões pelas quais ele não teria comunicado sua intenção a mais ninguém. Segundo Priestley, Franklin teria ficado receoso de ser ridicularizado. Em grande parte, isso se confirma, considerando que, até essa época, os textos de Franklin ainda estavam ganhando atenção dos filósofos naturais britânicos e ele mesmo afirmou que muitos riram de suas ideias (FRANKLIN, 1996, p.121). Isso ressalta como suas ideias levaram certo tempo para serem amplamente aceitas no contexto europeu, especialmente o britânico (CM). Um outro aspecto da descrição de Priestley - matéria, aliás, de controvérsia entre historiadores - é a presença de seu filho. De um lado, há a posição de que Franklin não o exporia ao perigo e, de outro, a suposição de que, como ele não julgava a situação perigosa - conforme a descrição do experimento da guarita 
no "Opiniões e conjecturas"-, ele não viu obstáculos nessa colaboração (MOURA, 2019, p.136). Ademais, a referência ao fato de que Franklin não conhecia a reprodução francesa denota, mais uma vez, particularidades da comunicação científica no século XVIII, em especial, a relativa demora que ideias e feitos da filosofia natural demoravam a chegar de um continente a outro, em contraste com a rápida divulgação nos dias atuais $(\mathrm{CM})$.

Por fim, parece ser em Priestley a possível origem para a anedota referente ao experimento da pipa. Ele menciona a descoberta "capital" da relação entre a eletricidade e os raios, descrevendo, logo em seguida, o experimento. De fato, grande parte das imagens que retratam a realização do experimento mostram Franklin na companhia de mais uma pessoa - como a gravura da figura 2 -, supostamente o filho mencionado por Priestley, o que corrobora a tese de que o episódio da pipa foi idealizado e levado a um status que não possuía em seu contexto original (CM).

\section{A aplicação da leitura contextualizada de fontes primárias (LC)}

Nesta seção, descrevo alguns detalhes da aplicação da leitura contextualizada de fontes primárias (LC) discutida na seção anterior, mencionando as etapas da fase de aplicação. Consoante ao relatado anteriormente, a LC foi aplicada em caráter piloto na disciplina "Evolução da Física", em uma turma do $1^{\circ}$ quadrimestre de 2018. Na ocasião, a turma tinha cerca de 25 alunos, distribuídos nos mais diferentes cursos.

Assim como a fase de construção, a fase de aplicação da LC envolveu cinco etapas. A primeira delas foi a discussão dos conhecimentos prévios. Foram destinadas duas aulas de duas horas para o trabalho com os conceitos de Gray, Du Fay e Nollet, bem como à apresentação do estado da eletricidade até o início do século XVIII. Em seguida, dentro desse mesmo ínterim, foram explorados os principais conceitos da teoria elétrica de Franklin. As aulas foram essencialmente expositivas, com espaço para debate e esclarecimento de dúvidas. Nessa etapa, o principal desafio foi condensar um grande número de ideias e eventos diferentes em algumas poucas horas, sem recair na superficialidade. De modo geral, o resultado pareceu satisfatório. 
A segunda etapa da aplicação, ocorrida nos primeiros trinta minutos de outra aula de duas horas foi a problematização. Nesse momento, foram mostradas cinco imagens retratando o experimento da pipa, todas muito posteriores ao experimento, incluindo aquelas das figuras 2 e 3 . Foi solicitado aos alunos que respondessem às primeiras perguntas descritas na seção "Quarta Etapa" deste capítulo, em relação ao que as imagens retratavam. Foram notadas particularidades como: a presença de mais uma pessoa além de Franklin; a chave ao final da linha que empinava a pipa, em alguns casos, sendo percebidas representações de faíscas; a ilustração de raios atingindo a pipa na maioria das figuras; entre outras. Em seguida, as demais perguntas da seção "Quarta Etapa" foram feitas: Franklin realmente fez o experimento da pipa?; Se sim, o que levou a propô-lo?; O que teria concluido? As respostas dos alunos mostraram que grande parte conhecia a anedota, afirmando que Franklin realizou o experimento para comprovar a natureza elétrica dos raios.

$\mathrm{Na}$ próxima hora, passamos à terceira etapa da aplicação, a leitura integral das fontes primárias, quando os trechos do quadro 3 foram entregues aos alunos. Optei por realizar essa etapa em sala de aula para garantir que houvesse tempo e oportunidade para esclarecer dúvidas e explicar termos ou ideias desconhecidas pelos alunos. Na ocasião, o principal esclarecimento foi sobre a figura 4, quando foi relacionada a descrição de Franklin sobre o experimento da guarita e os detalhes da figura. Esse momento ocupou os trinta minutos seguintes da aula.

$\mathrm{Na}$ aula seguinte, também com duas horas, prosseguimos à quarta etapa da aplicação, a leitura contextualizada. Com o auxílio de slides previamente preparados a partir dos subsídios para a LC discutidos no quadro 3 , os trechos das fontes foram recortados e esmiuçados, sendo dado tempo para novas questões e explicações. Dentre as atividades realizadas, foi analisada uma possível representação visual da pipa, com base nas descrições da carta de 1752 
(figura 5). Essa etapa teve a duração de uma hora e trinta minutos, aproximadamente. Nessa etapa, o principal desafio foi gerir o tempo destinado à discussão dos subsídios da LC. Como optei por não responder às dúvidas somente ao final, muitos questionamentos surgiram ao longo da aula. Um desses questionamentos referiu-se às razões pelas quais os trabalhos de Franklin não foram prontamente aceitos. Os alunos desconheciam aspectos da história da ciência estadunidense, pouco consolidada e prestigiada no século XVIII.

Figura 5 - Representação da pipa, feita com base nas descrições de Franklin.

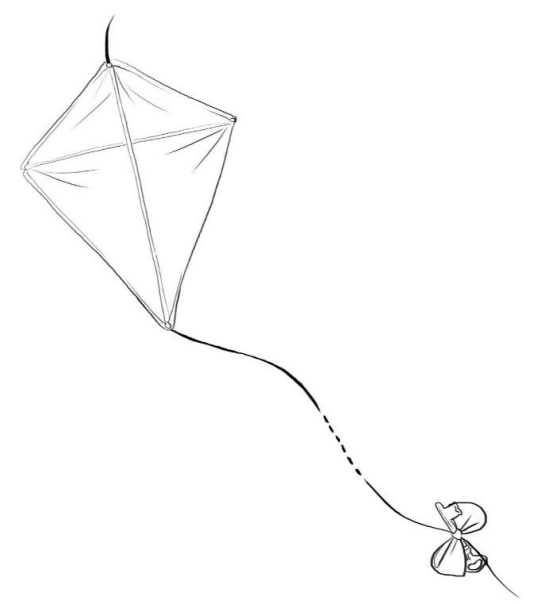

Fonte: elaborada por Jordi Pastor.

Nessa etapa de leitura contextualizada, os elementos dos contextos científico e metacientífico foram associados. Por exemplo, ao abordar as concepções de Franklin sobre o poder dos corpos pontudos, foi ressaltado como o conhecimento em eletricidade ainda era inicial nessa época, com várias propriedades que atualmente 
são tomadas como básicas ainda em processo de análise. De outra ponta, quando o experimento da guarita foi abordado, discuti seu significado dentro da teoria elétrica de Franklin, não como seu único e mais importante experimento, mas como integrante de uma discussão específica, relacionada a um conjunto mais amplo de concepções. Portanto, foi nessa etapa que a essência do ensino contextualizado transpareceu, uma vez que a análise do conteúdo das fontes a partir dos dois contextos contribuiu para um entendimento mais completo de seus significados e importâncias dentro do tema estudado.

A última etapa da aplicação foi a volta ao problema. As questões colocadas na etapa da problematização foram retomadas e respondidas em um amplo debate em sala de aula. Nesse momento, deu-se ênfase às questões da natureza da ciência $(\mathrm{NdC})$, mais especificamente aos elementos do contexto metacientífico listados no quadro 2. Considerei que essa seria a oportunidade de fechar a discussão, mostrando como as respostas às questões da problematização são complexas e ampliam a compreensão de senso comum sobre o trabalho de Franklin, a eletricidade no século XVIII e sobre o empreendimento científico. As anedotas, concluiu-se nos últimos trinta minutos da aula, podem esconder eventos, características e questões mais importantes e mais reveladores sobre a ciência que suas abordagens superficiais costumam destacar.

\section{Comentários finais}

A proposta de leitura contextualizada de fontes primárias (LC) descrita nas seções anteriores buscou oferecer possibilidades para a inserção de conteúdos da história da ciência em situações de ensino. Como uma proposta em constante construção, considero que sua estrutura, suas etapas e até mesmo sua fundamentação conceitual podem ser modificadas ao longo dos anos, 
por novas experiências e pressupostos. No contexto em que a proposta abrangendo Franklin e o experimento da pipa foi aplicada, ela foi bem sucedida em não apenas apresentar aos alunos escritos originais desse autor - até então não disponíveis em português como também aprofundar questões da natureza da ciência $(\mathrm{NdC})$, objetivo cada vez mais presentes nos trabalhos na interface entre história da ciência e ensino.

Conforme apontado no início desse capítulo, é possível que estruturas semelhantes à LC estejam sendo aplicadas, implícita ou explicitamente, por outros autores. Por exemplo, quando leio em Boss et al., (2016) a menção à introdução de notas explicativas nas traduções ou mesmo à inserção de uma breve biografia do autor estudado, isso ressoa com a etapa de estruturação da $L C$, em sua fase de construção, e à sua aplicação em si. Da mesma forma, quando Batista et al., (2015, p.688) afirma que a utilização didática das fontes "implica escolher excertos potencialmente relevantes, adequados ao contexto educacional, obter boas traduções e buscar alternativas para contornar eventuais dificuldades de compreensão", diversas etapas da construção da LC parecem semelhantes. Portanto, reafirmo que entendo a proposta de LC não como algo revolucionário ou novo, mas como uma tentativa de sistematizar o que já vem sendo feito, no intuito de organizar, nomear e discutir as ideias e diferentes passos para a utilização de fontes primárias.

Nesse sentido, os próximos estágios intencionam justamente a ampliação e aprimoramento da proposta de LC. As fontes primárias podem desempenhar um papel relevante no ensino e aprendizagem de aspectos da construção da ciência. Como reflexos das expectativas e pressupostos de seus autores e do momento em que foram produzidas, elas são recursos muito vantajosos para serem conhecidos apenas por especialistas. A LC pode ser um caminho para mostrar que, com adaptação e contextualização, as fontes primárias tem potencial para construir caminhos no ensino de ciências. 


\section{Referências}

ASSIS, A. K. T. Os fundamentos experimentais e históricos da eletricidade. Montreal: Apeiron, 2010.

BATISTA, G. L. F.; DRUMMOND, J. M. H. F.; FREITAS, D. B. Fontes primárias no ensino de física: considerações e exemplos de propostas. Caderno Brasileiro de Ensino de Física, v.32, n.3, p.663-702, dez., 2015.

BOSS, S. L. B.; CALUZI, J.J. Os conceitos de eletricidade vítrea e resinosa segundo Du Fay. Revista Brasileira de Ensino de Física, v.29, n.4, p.635-644, 2007.

BOSS, S. L. B. Tradução comentada de artigos de Stephen Gray (1666-1736) e reprodução de experimentos históricos com materiais de baixo custo - subsídios para o ensino de eletricidade. 2011. Tese (Doutorado em Educação para a Ciência) - Faculdade de Ciências, Universidade Estadual Paulista, Bauru, 2011.

BOSS, S. L. B.; ASSIS, A. K. T.; CALUZI, J. J. Stephen Gray e a descoberta dos condutores $e$ isolantes - tradução comentada de seus artigos sobre eletricidade e reprodução de seus principais experimentos. São Paulo: Cultura Acadêmica, 2012.

BOSS, S. L. B. et al., A utilização de traduções de fontes primárias na formação inicial de professores: breves considerações sobre a dificuldade de leitura e entendimento. In: GATTI, S. R. T.; NARDI, R. (orgs.). A história e a filosofia da ciência no ensino de ciências: a pesquisa e suas contribuições para a prática pedagógica em sala de aula. São Paulo: Escrituras Editora, 2016. cap.8, p.171-197. 
COHEN, I. B. Benjamin Franklin's Science. Cambridge-MA: Harvard University Press, 1990.

COOLEY, L. R. C. Natural Philosophy for Common and High Schools. New York: Charles Scribner's Sons, 1882.

FORATO, T. C. M. A natureza da ciência como saber escolar: um estudo de caso a partir da história da luz. 2009. Tese (Doutorado em Educação) - Faculdade de Educação, Universidade de São Paulo, São Paulo, 2009.

FRANKLIN, B. A letter of Benjamin Franklin, Esq; to Mr. Peter Collinson, F.R.S. concerning an electrical kite. Philosophical Transactions, v.47, p.565-567, 1751-1752.

FRANKLIN, B. Experiments and observations on electricity, made at Philadelphia in America. London: David Henry, 1769.

FRANKLIN, B. The autobiography of Benjamin Franklin. Mineola/New York: Dover Publications, 1996.

GALILEI, G. Ciência e fé. São Paulo: Nova Stella Editorial, 1988.

GIL-PÉREZ, D. et al., Para uma imagem não deformada do trabalho científico. Ciência e Educação, v.7, n.2, p.125-53, 2001.

GROSSMAN, E. Why translation matters. New Haven/London: Yale University Press, 2010.

GUERRINI, A. Translation as a way of life. Isis, v.109, n.4, p.747752, 2018. 
HEILBRON, J. L. Electricity in the 17th and 18th centuries: a study of early modern physics. Berkeley/ Los Angeles/ London: University of California Press, 1979.

HODSON, D. Nature of Science in the science curriculum: origin, development, implications and shifting emphases. In: MATTHEWS, M. R. (ed.). International handbook of research in history, philosophy and science teaching. Dordrecht: Springer, 2014. cap.28, p.911-970.

JARDIM, W.; GUERRA, A. República das letras, academias e sociedades científicas no século XVIII: a garrafa de Leiden e a ciência no ensino. Caderno Brasileiro de Ensino de Física, v.34, n.3, p.774-797, dez., 2017.

KLASSEN, S. A theoretical framework for contextual science teaching. Interchange, v.37, n.1-2, p.31-62, 2006.

KLASSEN, S The application of historical narrative in science learning: the Atlantic cable story. Science \& Education, v.16, p.335-352, 2007.

KLASSEN, S. The construction and analysis of a science story: a proposed methodology. Science \& Education, v.18, p.401-423, 2009.

KLASSEN, S. The relation of story structure to a model of conceptual chance in science learning. Science \& Education, v.19, p.305-317, 2010.

KRAGH, H. Introdução à historiografia da ciência. Porto: Porto Editora, 2001. 
MAGNAGHI C. P.; ASSIS, A. K. T. Sobre a eletricidade excitada pelo simples contato entre substâncias condutoras de tipos diferentes - uma tradução comentada do artigo de Volta de 1800 descrevendo sua invenção da pilha elétrica. Caderno Brasileiro de Ensino de Física, v.25, n.1, p.118-140, abr., 2008.

MOURA, B. A.; BOSS, S. L. B. Thomas Young e o resgate da teoria ondulatória da luz: uma tradução comentada de sua Teoria sobre Luz e Cores. Revista Brasileira de Ensino de Física, v.37, n.4, p.4203, 2015.

MATTHEWS, M. R. (ed.). International handbook of research in history, philosophy and science teaching. Dordrecht: Springer, 2014.

MOURA, B. A. Formação crítico-transformadora de professores de física: uma proposta a partir da história da ciência. 2012. Tese (Doutorado em Ensino de Ciências) - Instituto de Física, Faculdade de Educação, Universidade de São Paulo, 2012.

MOURA, B. A. As contribuições de Benjamin Franklin para a eletricidade no século XVIII. Física na Escola, v.16, n.2, p.27-35, 2018.

MOURA, B. A. A filosofia natural de Benjamin Franklin: tradução de cartas e ensaios sobre a eletricidade e a luz. São Bernardo do Campo: EdUFABC, 2019.

MOURA, B. A. SILVA, C. C. Critical and transformative teachers: a rationale for history and philosophy of science in science teacher education. In: PRESTES, M. E. B.; SILVA, C. C. (eds.). Teaching science with context - historical, philosophical, and sociological approaches. Dordrecht: Springer, 2018. cap.1, p.3-13. 
MOURA, B. A. SILVA, C. C. Abordagem multicontextual da história da ciência: uma proposta para o ensino de conteúdos históricos na formação de professores. Revista Brasileira de História da Ciência, v.7, n.2, p.336-348, jul-dez., 2014.

PRIESTLEY, J. The history and present state of electricity, with original experiments. London: J. Dodsley, J. Johnson, B. Davenport, T. Cadell, 1767.

SCHIFFER, H.; GUERRA, A. Electricity and vital force: discussing the nature of science through a historical narrative. Science $\mathbb{E}$ Education, v.24, p.409-434, 2015.

SCHOFIELD, R. The enlightenment of Joseph Priestley: a study of his life and work from 1733 to 1773. Philadelphia: The Pennsylvania State University Press, 1997.

SILVA, A. P. B.; GUERRA, A. História da ciência e ensino - fontes primárias e propostas para a sala de aula. São Paulo: Editora Livraria da Física, 2015.

SILVA, A. P. B.; SILVEIRA, A. F. História da ciência e ensinofontes primárias. São Paulo: Editoria Livraria da Física, 2018.

SILVA, C. C. Jean Antoine Nollet's contributions to the institutionalization of physics during the $18^{\text {th }}$ century. In: KRAUSE, D.; VIDEIRA, A. (eds.). Brazilian studies in philosophy and history of science: an account of recent works. Dordrecht: Springer, 2011, cap.8, p.131-140.

SILVA, C. C.; PIMENTEL, A. C. Uma análise da história da eletricidade presente em livros didáticos: o caso de Benjamin Franklin. 
Caderno Brasileiro de Ensino de Física, v.25, n.1, p.141-159, 2008.

SILVA, C. C.; HEERING, P. Re-examining the early history of the Leiden jar: stabilization and variation in transforming a phenomenon into a fact. History of Science, v.56, n.3, p.314-342, 2018.

STINNER, A. The large context problem (LCP) approach. Interchange, v.37, n.1-2, p.19-30, 2006.

TEIXEIRA, E. S.; GRECA, I. M.; FREIRE JR., O. Uma revisão sistemática das pesquisas publicadas no Brasil sobre o uso didático de história e filosofia da ciência no ensino de física. In: PEDUZZI, L. O. Q.; MARTINS, A. F. P.; FERREIRA, J. M. H. (orgs.). Temas de história e filosofia da ciência no ensino. Natal: EdUFRN, 2012, cap.1, p.9-40.

VYGOTSKY, L. Pensamento e linguagem. 4. ed. Rio de Janeiro: Martins Fontes, 2008.

XAVIER, A. M.; STEIL, L. J. Quadrimestre ideal: dispositivo de controle de tempo no currículo da UFABC. Educação e Pesquisa, v.44, p.1-18, 2018. 